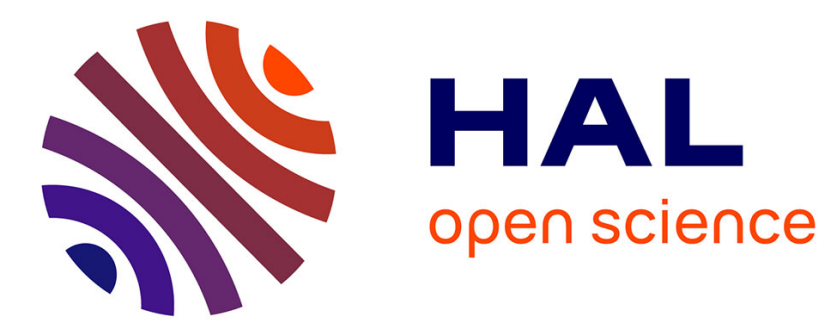

\title{
On the deformation mechanism of olivine single crystals at lithospheric temperatures: an electron tomography study
}

Alexandre Mussi, Maula Nafi, Sylvie Demouchy, Patrick Cordier

\section{- To cite this version:}

Alexandre Mussi, Maula Nafi, Sylvie Demouchy, Patrick Cordier. On the deformation mechanism of olivine single crystals at lithospheric temperatures: an electron tomography study. European Journal of Mineralogy, 2015, European Journal of Mineralogy, 27 (6), pp.707-715. 10.1127/ejm/2015/00272481 . hal-01277821

\section{HAL Id: hal-01277821 \\ https://hal.science/hal-01277821}

Submitted on 16 Jul 2019

HAL is a multi-disciplinary open access archive for the deposit and dissemination of scientific research documents, whether they are published or not. The documents may come from teaching and research institutions in France or abroad, or from public or private research centers.
L'archive ouverte pluridisciplinaire HAL, est destinée au dépôt et à la diffusion de documents scientifiques de niveau recherche, publiés ou non, émanant des établissements d'enseignement et de recherche français ou étrangers, des laboratoires publics ou privés. 


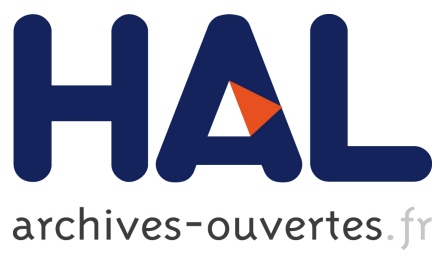

\section{No title \\ Alexandre Mussi, Maula Nafi, Sylvie Demouchy, Patrick Cordier}

\section{To cite this version:}

Alexandre Mussi, Maula Nafi, Sylvie Demouchy, Patrick Cordier. No title. European Journal of Mineralogy, E Schweizerbart Science Publishers, 2015, European Journal of Mineralogy, 27 (6), pp.707715. $10.1127 /$ ejm/2015/0027-2481 . hal-01277821

\section{HAL Id: hal-01277821 \\ https://hal.archives-ouvertes.fr/hal-01277821}

Submitted on 16 Jul 2019

HAL is a multi-disciplinary open access archive for the deposit and dissemination of scientific research documents, whether they are published or not. The documents may come from teaching and research institutions in France or abroad, or from public or private research centers.
L'archive ouverte pluridisciplinaire HAL, est destinée au dépôt et à la diffusion de documents scientifiques de niveau recherche, publiés ou non, émanant des établissements d'enseignement et de recherche français ou étrangers, des laboratoires publics ou privés. 
Eur. J. Mineral.

2015, 27, 707-715

Published online 1 September 2015

\title{
On the deformation mechanism of olivine single crystals at lithospheric temperatures: an electron tomography study
}

\author{
AleXANDRe MUSSI ${ }^{1, *}$, MAUla NAFI $^{1}$, SYLVIE DEMOUCHY $^{2}$ and PATRICK CORDIER ${ }^{1}$ \\ ${ }^{1}$ Unité Matériaux et Transformations, UMR 8207 CNRS-Université Lille1, F-59655 Villeneuve d'Ascq, France \\ *Corresponding author, e-mail: alexandre.mussi@univ-lille1.fr \\ ${ }^{2}$ Géoscience Montpellier, UMR 5342 CNRS - Université Montpellier, F-34095 Montpellier, France
}

\begin{abstract}
We present an electron tomography study of dislocations in deformed olivine single crystals, at $c a$. $0.5 T_{\mathrm{m}}$, along two distinct orientations. The easiest slip systems are [001](100) and [001]\{110\}. Disorientating a single crystal away from easy glide conditions leads to massive cross-slip, which generates three-dimensional dislocations, and thus contributes to hardening. Fast motion of curved non-screw dislocation in those planes leaves long straight screw dislocations which bear lattice friction and control plastic strain. We have identified several hardening mechanisms. Non-screw [001] dislocations interact elastically to form dipoles. Recovery mechanisms leading to dipole annihilation are observed, but they are slow at those temperatures and produce numerous sessile loops. These loops represent obstacles for gliding dislocations. Interactions between dislocations and sessile loops produce sessile segments (super jogs), which efficiently impede dislocation motions.
\end{abstract}

Key-words: olivine; dislocation; cross-slip; rheology; plasticity; electron tomography; hardening.

\section{Introduction}

The rheology of the lithosphere is of fundamental importance in geodynamics from both the point of view of plate tectonics and of mantle convection. The strength of the uppermost part of Earth's mantle, just below the discontinuity of Mohorovičić (Moho) which separates the crust and the mantle, is constrained by the rheology of olivine. However, the plasticity of olivine is still poorly understood under the relatively low temperatures (i.e. close to $0.5 T_{\mathrm{m}}$ ) relevant to the shallow mantle lithosphere. Constitutive equations obtained from laboratory experiments (Raterron et al., 2004, 2012; Mei et al., 2010; Demouchy et al., 2013a and b, 2014) yield a wide range of rheologies. In particular, it has been shown that the flow laws from Mei et al. (2010) predict a lithosphere that is too strong to match the flexures observed at Hawaii (Zhong \& Watts, 2013). The flow laws recently proposed by Demouchy et al. (2013a and b, 2014) suggest lower stresses, $30 \mathrm{MPa}$ (at $800^{\circ} \mathrm{C}, 10^{-14} \mathrm{~s}^{-1}$ and $\left.300 \mathrm{MPa}\right)$, to be compared with 300 MPa predicted by Mei et al. (2010) under similar conditions (at $800^{\circ} \mathrm{C}, 10^{-14} \mathrm{~s}^{-1}$ and 4-9 GPa). Understanding the deformation mechanisms appears to be essential to constrain extrapolation of laboratory-based flow laws to natural conditions; however, detailed studies of olivine under relatively low temperatures are scarce. Raleigh (1968) has characterized [001]\{110\} and [001](100) slip systems for temperatures below $1,000^{\circ} \mathrm{C}$, analyzing the slip bands on the surfaces of single crystals of deformed olivine. Phakey et al. (1972) used transmission electron microscopy (TEM) to study the microstructures of single crystals deformed at low temperature; the authors observed the $[001]\{110\}$ slip system as well as the occurrence of the [001](100) and [001](010) slip systems, at $800^{\circ} \mathrm{C}$. Gaboriaud et al. (1981) have verified that, for deformation temperatures between $20^{\circ} \mathrm{C}$ and $600^{\circ} \mathrm{C}$, deformed olivine exhibits mostly straight [001] screw dislocations suggesting a high lattice friction of this character at such low temperatures. For temperatures higher than $600^{\circ} \mathrm{C}$, the authors have reported glide of [001] dislocations in the (100) planes and in few $\{110\}$ planes. These observations raise fundamental questions which have not been solved in olivine yet. One is related to the extreme plastic anisotropy exhibited by olivine at low temperature, where the easy glide involves only one direction: [001]. Under such conditions, the origin of hardening observed at low temperature in deformed single crystals by Demouchy et al. (2013b) is not clear. Indeed, in most materials, strain hardening originates mostly from interactions between intersecting slip systems with distinct dislocations, which react and form junctions (Madec et al., 2002; Bulatov et al., 2006). This cannot be applied to olivine single crystals deformed at low temperature.

Recently, we have shown that electron tomography could be applied to dislocations in olivine to expand our analytical capabilities (Mussi et al., 2014, 2015). We have 
emphasized the importance [001] $\{110\}$ glide (Mussi et al., 2014) and identified for the first time the collinear annihilation as a potential hardening mechanism in olivine (Mussi et al., 2015). Here we take advantage of this new technique to further investigate the mechanisms leading to dislocation interactions in olivine at low temperature.

\section{Experimental procedure}

\subsection{Description of samples and deformation experiments}

In this study, we focus on two deformation experiments conducted by Demouchy et al. (2013b) on single crystals of olivine at $c a .0 .5 T_{\mathrm{m}}$ : PoEM 9 and PoEM 11. Sample PoEM 9 was orientated to activate the $[001](100),[001](110)$ and $[100](001)$ slip systems. PoEM 11 was orientated to activate [001](010), [001]\{140\}, [001]\{130\} and [001] $\{120\}$ glides. The corresponding Schmid factors (providing the resolved shear stress for a given slip system) are reported in Table 1.

The single crystals were cored from San Carlos olivine (Arizona, USA) with cylindrical shapes $(6.32 \mathrm{~mm}$ long and $4.19 \mathrm{~mm}$ diameter for PoEM 9, $6.61 \mathrm{~mm}$ long and $4.20 \mathrm{~mm}$ diameter for PoEM 11, see Demouchy et al., 2013b). They have been deformed in compression, using a high-temperature, high-pressure gas-vessel apparatus (Paterson, 1970; Paterson, 1990) at Geosciences Montpellier (University of Montpellier), with an argon confining pressure of 300 MPa. The PoEM 9 and PoEM 11 specimens have been deformed in axial compression at $806^{\circ} \mathrm{C}\left(0.55 T_{\mathrm{m}}\right)$ and $850^{\circ} \mathrm{C}\left(0.57 T_{\mathrm{m}}\right)$, with strain rates of $5.1 \times 10^{-5} \mathrm{~s}^{-1}$ and $7.1 \times 10^{-6} \mathrm{~s}^{-1}$, respectively.

\subsection{Transmission electron microscopy}

Slices from the deformed samples were mechanically thinned down to a thickness of $30 \mu \mathrm{m}$. To reach electron transparency, the foils were Ar-ion milled with a Gatan ${ }^{\circledR}$ DuoMill TM model 600. To ensure electron conduction, each thin foil

Table 1. Schmid factors for the [001] $\{h k 0\}$ slip systems corresponding to the PoEM 9 and PoEM 11 samples deformed in axial compression tests (Demouchy et al., 2013b).

\begin{tabular}{|c|c|c|c|}
\hline & $\begin{array}{l}\text { Compression } \\
\text { axis before } \\
\text { compression }\end{array}$ & & $\begin{array}{l}\text { Compression } \\
\text { axis before } \\
\text { compression }\end{array}$ \\
\hline PoEM 9 & {$\left[\begin{array}{lll}1 & 0 & 1\end{array}\right]$} & PoEM 11 & {$\left[\begin{array}{lll}5 & 19 & 10\end{array}\right]$} \\
\hline (100) & 0.49 & (100) & 0.03 \\
\hline (110) & 0.44 & (110) & 0.15 \\
\hline$(1 \overline{1} 0)$ & 0.44 & $(1 \overline{1} 0)$ & 0.09 \\
\hline (120) & 0.36 & (120) & 0.21 \\
\hline$(1 \overline{2} 0)$ & 0.36 & $(1 \overline{2} 0)$ & 0.16 \\
\hline (130) & 0.28 & (130) & 0.25 \\
\hline$(1 \overline{3} 0)$ & 0.28 & $(1 \overline{3} 0)$ & 0.21 \\
\hline (140) & 0.23 & (140) & 0.26 \\
\hline$(1 \overline{4} 0)$ & 0.23 & $(1 \overline{4} 0)$ & 0.23 \\
\hline (010) & Negligible & (010) & 0.28 \\
\hline
\end{tabular}

was coated with a thin carbon layer. The TEM analyses were conducted with a FEI ${ }^{\circledR}$ Tecnaï $\mathrm{G}^{2} 20$ twin microscope operating at a $200 \mathrm{kV}$ accelerating voltage with $\mathrm{LaB}_{6}$ filament. Dislocations were analyzed using the weak-beam dark-field (WBDF) method. This technique enables us to obtain high spatial resolution micrographs (4 $\mathrm{nm}$ resolution), while keeping a high signal to noise ratio (Mussi et al., 2014). The "Electron Diffraction" software (Morniroli \& Steeds, 1982) enables us to calculate the simulated kinematical diffraction patterns. In this study, the orthorhombic $(a=4.752 \AA, b=10.193 \AA, c=5.977 \AA$; Hazen, 1976) crystal structure of olivine is described within the Pbnm space group. Precession (Vincent \& Midgley, 1994) was performed with a "Spinning Star" precession module from the Nanomegas Company and was associated with the WBDF mode (WBDF-P) to homogenize the image contrast (Rebled et al., 2011; Mussi et al., 2014, 2015). A precession angle of $0.1^{\circ}$ is sufficient to highly reduce the oscillating contrast of inclined dislocations and the thickness fringes, and this angle is small enough for the electron beam not to be masked by the objective aperture. Electron tomography was performed with a double-tilt sample holder with a maximal angular range of $\pm 60^{\circ}$. The obtained tilted series have been manually centred within one-pixel accuracy, and then filtered with the ImageJ software to enhance the dislocation contrast, and improve the background and dislocation contrast homogeneity. The 3D images have been generated with two reconstruction algorithms: the simultaneous iterative reconstruction technique algorithm (Penczek et al., 1992) used with the Gatan ${ }^{\circledR}$ 3D reconstruction software, and the weighted back-projection algorithm (Herman et al., 1976) used with the TomoJ plugin (Messaoudi et al., 2007) accessible in ImageJ.

\section{Results}

Several areas have been analyzed in this study: seven from PoEM 9 and six from PoEM 11. On average, domain sizes are $2.4 \pm 0.7 \mu \mathrm{m}$ by $1.6 \pm 0.4 \mu \mathrm{m}$ for PoEM 9 and $2.0 \pm$ $0.2 \mu \mathrm{m}$ by $1.3 \mu \mathrm{m} \pm 0.1 \mu \mathrm{m}$ for PoEM 11. The microstructures are composed of numerous [001] straight screw dislocations, entanglements and loops. Tomography reconstructions enable us to characterize the dislocation glide planes. A colour code linked to the glide planes is given in Table 2 . Dislocations coloured in red and orange are both lying on sessile planes. We have measured dislocation densities of the order of $1.3 \times 10^{13} \mathrm{~m}^{-2}$ for PoEM 9, for $10.1 \%$ of strain and a higher dislocation density of $1.1 \times 10^{14} \mathrm{~m}^{-2}$ for PoEM 11 for $21.5 \%$ of strain. In PoEM 11, we have mostly focused on areas where entanglements of non-screw dislocations are observed, so the dislocation density reported here represents an upper bound of the overall microstructure.

\subsection{Sample PoEM 9}

A typical microstructure of PoEM 9 is presented on Fig. 1. The microstructure is dominated by straight segments of [001] screw dislocations (in yellow in Fig. 1b). It is not 
Table 2. Colour code used to indicate the planes containing indexed dislocation segments.

\begin{tabular}{|c|c|c|c|c|c|}
\hline Dislocation planes & $(100)$ & $(140)$ & $(130)$ & $(120)$ & $(1 \overline{1} 0)$ \\
\hline Dislocation colors & Black & Light purple & Light green & Light blue & Light grey \\
\hline Dislocation planes & $(010)$ & $(1 \overline{4} 0)$ & $(1 \overline{3} 0)$ & $(1 \overline{2} 0)$ & Sessile $(l \neq 0)\{h k l\}$ planes \\
\hline Dislocation colors & Dark grey & Dark purple & Dark green & Dark blue & Red or orange \\
\hline
\end{tabular}
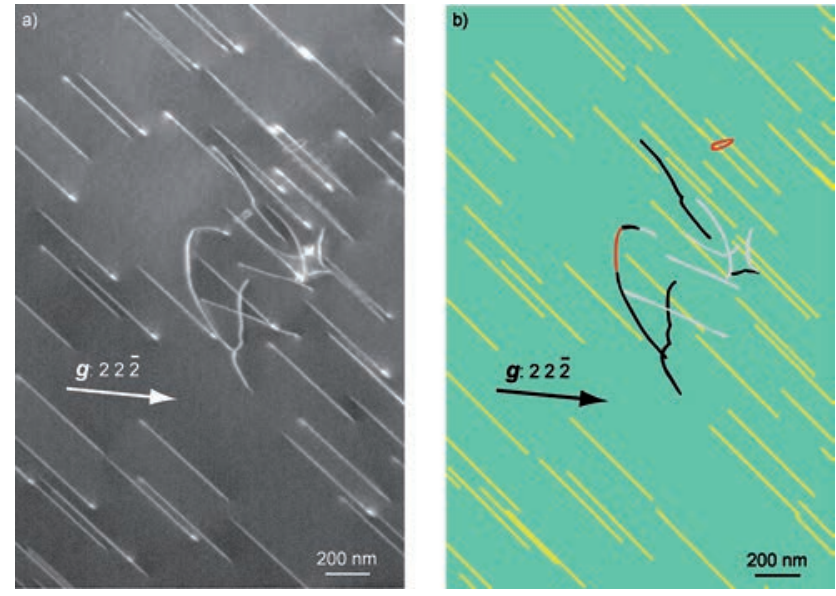

Fig. 1. Indexation of a tilted series of PoEM 9. (a) Micrograph in WBDF-P conditions, with g: $22 \overline{2}$, showing very few non-screw dislocation segments; (b) corresponding indexed micrograph (colours are linked to the dislocation glide and climb planes, as specified on Table 2), where (100), (1 $\overline{1} 0)$ glide planes and sessile planes are characterized (yellow dislocations could not be indexed due to their straight-lined configurations). (online version in colour)

possible to identify the glide plane of these yellow dislocations since only one orientation segment is available. However, with tomography we can obtain information on a sessile loop, a sessile dislocation segment and non-screw [001] dislocation segments gliding in (100) and (110) (see Table 2 and Fig. 1b). In PoEM 9, most [001] screw dislocations observed are perfectly rectilinear. We have noted very few cross-slip events and loops. Identified glide planes are mostly of the (100) and $\{110\}$ type. Some zones more populated with non-screw dislocations (i.e., generally lower than $1 \mu \mathrm{m}$ in length) can be observed, however they are quite rare.

\subsection{Sample PoEM 11}

The microstructure of PoEM 11 is more complex. Numerous areas with concentrations of non-screw dislocations and entanglements are observed as illustrated in Fig. 2. Detailed characterizations using tomography show that many dislocations exhibit very intricate geometries. Their lines are composed of segments belonging to different planes (highlighted by different colours in Figs 2 and 3 ). We identify $[001](110) /[001](1 \overline{1} 0)$ cross-slip events and two $[001](110) /[001](1 \overline{1} 0) /[001](120)$ multiple cross-slip events in Fig. 3 (which is extracted from the lower
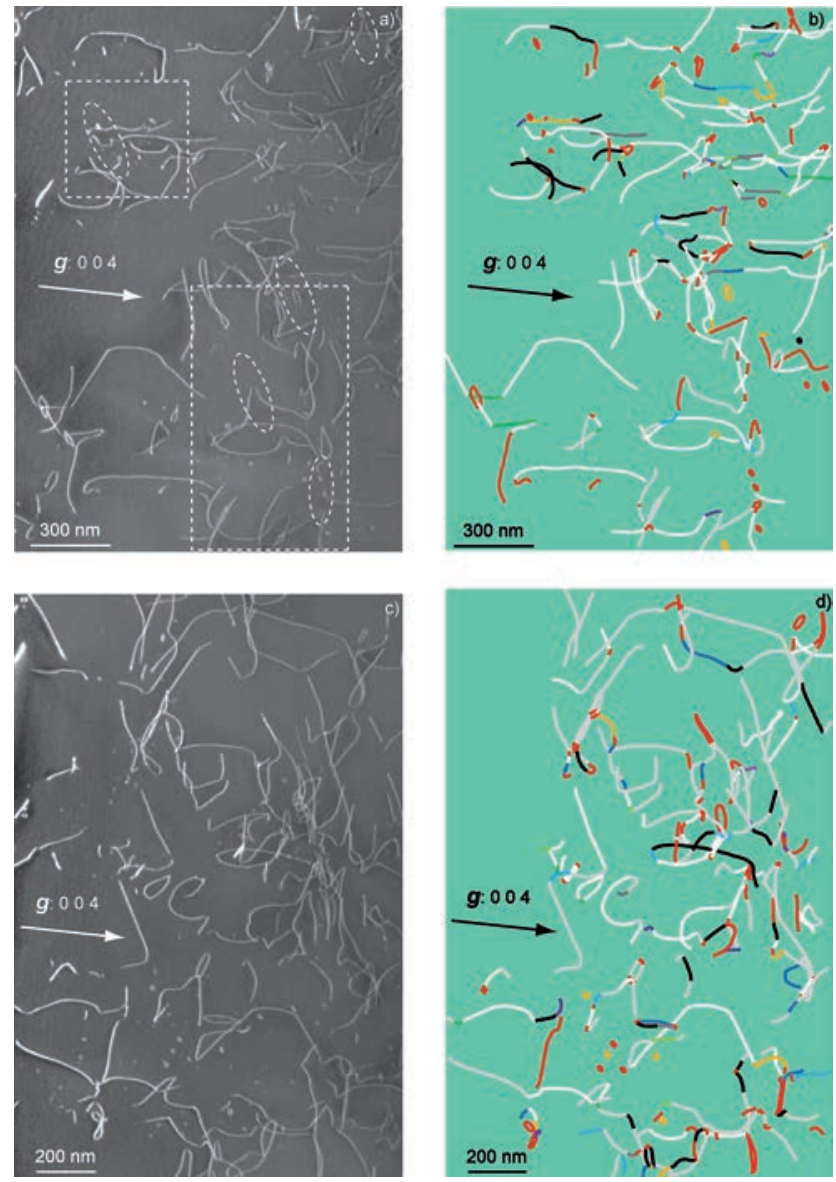

Fig. 2. Indexation of two tilted series of PoEM 11. (a) WBDF-P image observed with $\mathbf{g :}$ :004, the two dashed rectangles correspond to two regions magnified in Fig. 3c (bottom) and 7c (top), the five dashed ellipses point out sessile dislocation segments that are geometrically related to neighbouring sessile loops; (b) corresponding indexation where colours are linked to the dislocation glide and climb planes given in Table 2; one can notice a dominance of white (110) glide planes, and red and orange segments are sessile; (c) same WBDF-P conditions, but in another area; (d) corresponding indexation, colour code is given Table 2 (dominance of light grey (110) glide planes). (online version in colour)

right corner of Fig. 2a). Several glide planes have been characterized within these areas $((100),\{110\}$, $\{120\},\{130\},\{140\}$ and $(010))$, with a majority of $\{110\}$ planes (Figs 2 and 3). Another important observation is linked to the dislocations coloured in red and orange, which are lying on sessile planes. It is worth noticing that numerous sessile dislocation segments can be geometrically related to neighbouring sessile loops. 

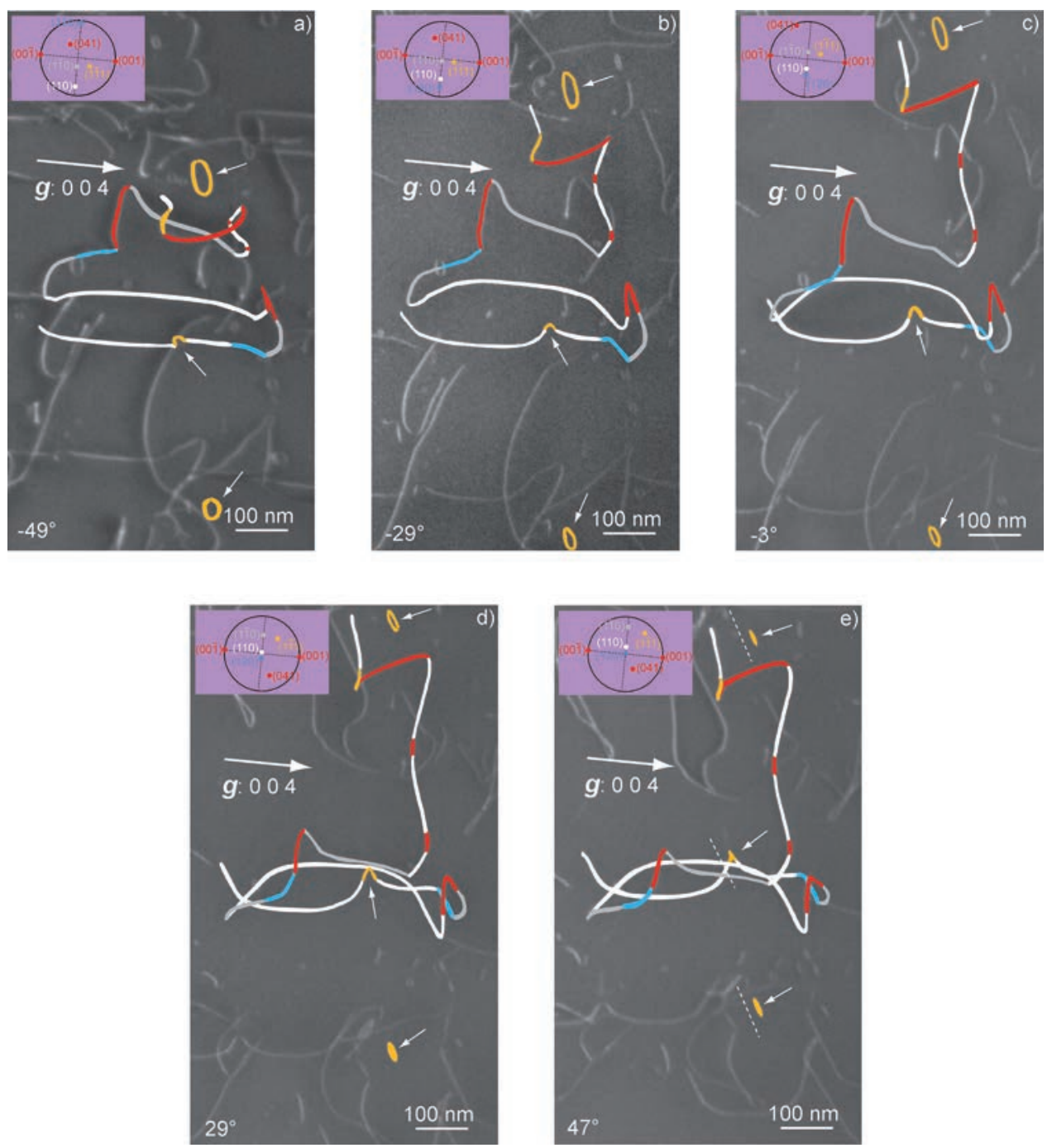

Fig. 3. Sample PoEM 11: detailed analysis of a portion of Fig. 2. Micrographs in WBDF-P conditions obtained with the 004 diffraction vector, with the corresponding stereographic projection on the top left corner: (a) the two coloured loops lie practically in the projection plane for a tilt angle of $-49^{\circ}$ (the colour code for the dislocation glide planes is given in Table 2) which is also the case for the orange dislocation segment in the middle of the micrograph (see white arrows); (b) micrograph tilted at $-29^{\circ}$; (c) $-3^{\circ}$ (area extracted from Fig. 2a); (d) 29 ; (e) with a projection angle of $47^{\circ}$ the planes of the two dislocation loops are approximately edge-on. The traces of the lying planes are highlighted by white dashed lines. This is also the case for the dislocation segment coloured in orange in the middle of the micrograph, which likely results from the interaction of the white dislocation with a loop similar to the one noted by the white arrows. (online version in colour)

The occurrence of those sessile loops is pervasive and we can distinguish several families. Some small sessile loops form strings (Fig. 4a). They are clearly related to the collapse after pinching of very elongated, sometimes twisted (Fig. 4b), loops. However, all loops do not exhibit these characteristics. On the tilted series shown in Fig. 5, we observe four [001] sessile loops, which are approximately parallel and hence cannot result from the breakage described above. A third dislocation loops family, made of very small strings of debris (at the resolution limit of WBDF) is observed in association with a pinned dislocation in Fig. 6. The corresponding reconstructed volume tilted to $116^{\circ}$ (Fig. 6c) shows that the pinned dislocation glides on the (110) plane.
All the glide, climb and cross-slip planes characterized in PoEM 9 and PoEM 11 are summarized in Table 3.

\section{Discussion}

The first striking observation is linked to the marked differences between the microstructures observed in the two samples investigated, which differ only by their loading axis. This raises the question on the importance of plastic anisotropy in olivine and will be discussed first. In this study, we focus on the mechanisms that may lead to dislocations interactions and strain hardening. We will then 

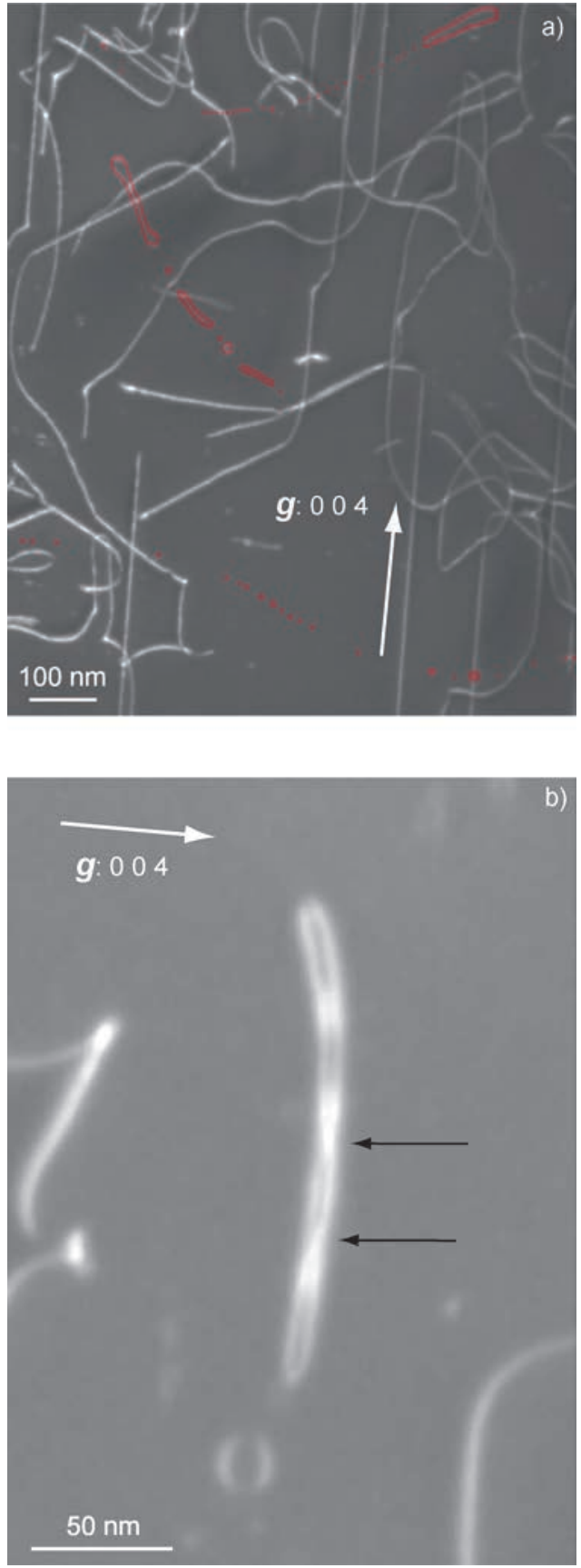

Fig. 4. Sample PoEM 11: break-up of dislocation dipoles into strings of dislocation loops. Micrograph in WBDF-P condition, with g: 004, where: (a) three dislocation dipoles (coloured in red) are annihilating by climb and two of them are practically totally annihilated; (b) magnification of a dipole loop in the process of pinching (arrows) just before the formation of strings of loops. (online version in colour)

discuss the significance of the pervasive occurrence of dislocations loops observed in these samples.

\subsection{Comparison between PoEM 9 and PoEM 11}

The PoEM 9 and PoEM 11 single crystals have been compressed at equivalent temperatures, similar strain
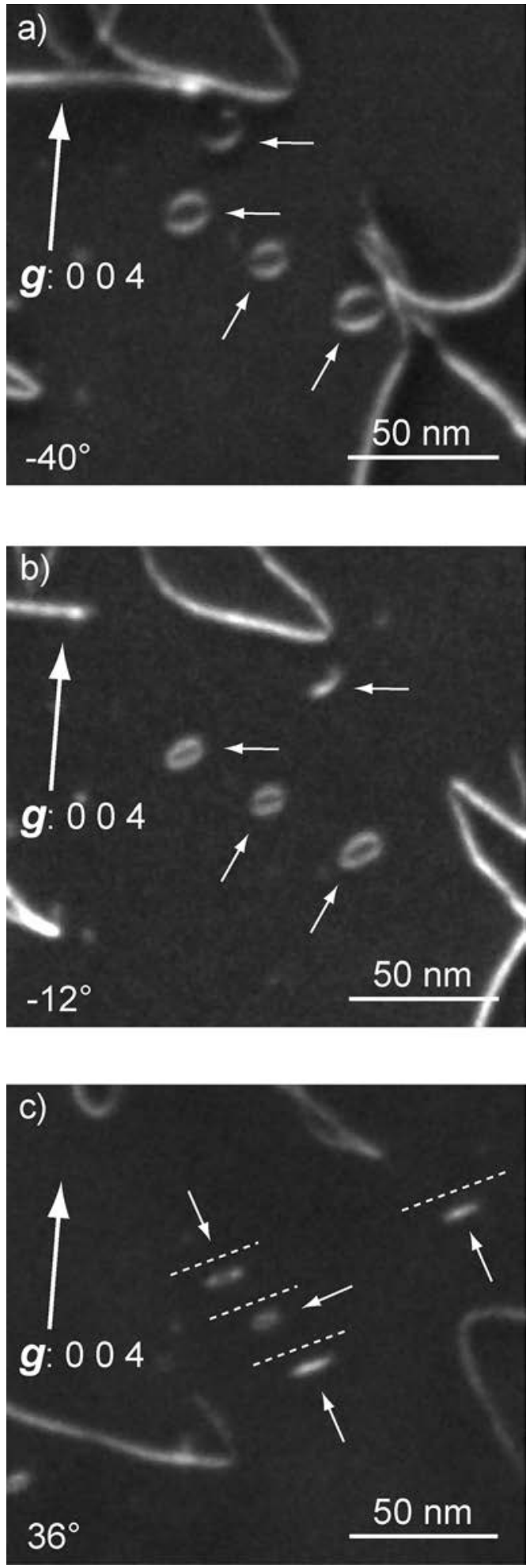

Fig. 5. Parallel dislocation loops in PoEM 11. WBDF-P images obtained with the 004 diffraction vector: (a) the four dislocation loops lie practically in the projection plane for a tilt angle of $-40^{\circ}$ (indicated by white arrows); (b) projection angle of $-12^{\circ}$; (c) the four loops are approximately edge-on and parallel (the traces of the lying planes are highlighted by white dashed lines), with a projection angle of $36^{\circ}$ (as the Burgers vector [001], parallel to the $\mathbf{g}$ vector, is not contained in the plane of the loops, they are sessile). 

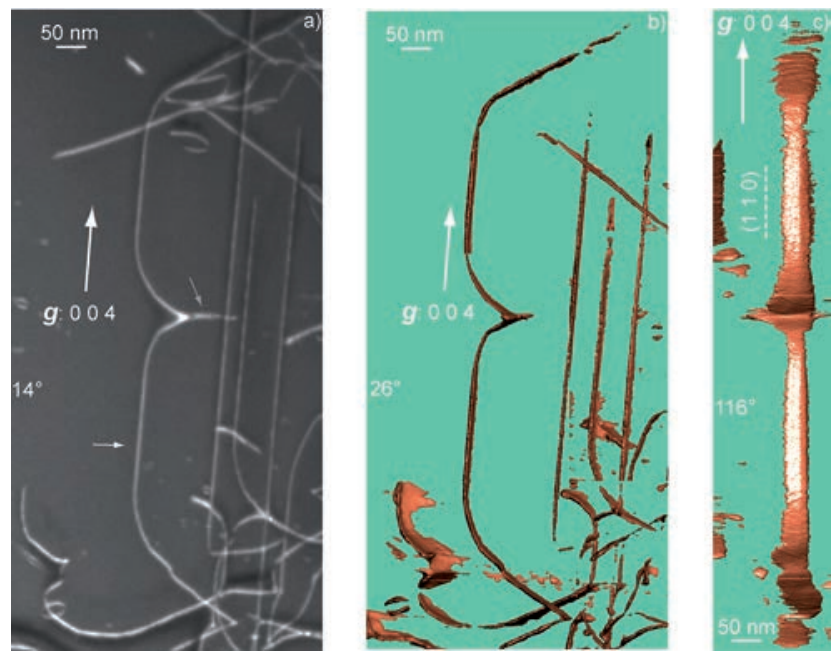

Fig. 6. Pinned dislocation in PoEM 11. (a) WBDF-P micrograph, tilted at $14^{\circ}$, diffraction vector: 004, showing a pinned [001] screw dislocation (indicated by a white arrow), leaving debris (at the resolution limit of WBDF) in its wake (indicated by a light grey arrow); (b) corresponding electron tomography reconstruction volume (tilted at $26^{\circ}$ ); (c) reconstructed volume tilted at $116^{\circ}$, where the glide plane of the pinned dislocation is edge-on. It corresponds to (110). (online version in colour)

Table 3. Summary of the number of the glide planes, climb planes and cross-slip planes characterized in PoEM 9 and PoEM 11.

\begin{tabular}{lclc}
\hline PoEM 9 & $\begin{array}{l}27.9 \mu \mathrm{m}^{2} \text { total } \\
\text { area }\end{array}$ & PoEM 11 & $\begin{array}{l}16.6 \mu \mathrm{m}^{2} \text { total } \\
\text { area }\end{array}$ \\
\hline$(100)$ & 20 & $(100)$ & 57 \\
$(010)$ & 0 & $(010)$ & 17 \\
$\{110\}$ & 40 & $\{110\}$ & 335 \\
$\{120\}$ & 0 & $\{120\}$ & 46 \\
$\{130\}$ & 2 & $\{130\}$ & 20 \\
$\{140\}$ & 1 & $\{140\}$ & 26 \\
Climb & 6 & Climb & 175 \\
Cross-slip & 11 & Cross-slip & 306 \\
\hline
\end{tabular}

rates, but along two distinct orientations (Table 1). From a purely geometrical point of view, Table 1 shows that PoEM 9 favours activation of [001](100) and [001]\{110\} followed by glide in $\{120\},\{130\}$ and $\{140\}$. The microstructure is very consistent with these constraints since glide appears to be essentially planar in PoEM 9, with the vast majority of dislocations gliding in (100) and $\{110\}$ (Table 3). Some evidence for cross slip is however observed. The situation is more complex for PoEM 11 where several planes are solicited at a comparable level: (010), $\{140\},\{130\}$ or $\{120\}$, i.e. their Schmid factor is between 0.2 and 0.3 . However, most dislocations (more than $60 \%$ of the 500 characterized glide planes) are found to glide in $\{110\}$, which is only marginally solicited (i.e., Schmid factor of about 0.1). This demonstrates that [001] glide in $\{110\}$ is by far the easiest slip system under these experimental conditions. The (100) plane represents $10 \%$ of the characterized glide planes in PoEM 11. Since this plane also corresponds to a very low resolved shear stress, we can conclude that [001](100) is the second easiest slip system. From this point of view, PoEM 9 and PoEM 11 demonstrate very consistently that $[001]\{110\}$ represents the easiest slip system in olivine at $c a .0 .5 T_{\mathrm{m}}$, followed by [001](100). This is consistent with the conclusions of Phakey et al. (1972), describing deformation at $800^{\circ} \mathrm{C}$ of single crystals with orientations close to the one of PoEM 9. However, the implications of this strong plastic anisotropy are further illustrated.

Being solicited to activate easy slip, PoEM 9 exhibits mostly a planar dislocation microstructure (Fig. 1) dominated by straight screw segments and their mobility strongly controls the olivine plasticity. The microstructure of PoEM 11 is very different (compare Figs 1 and 2). Electron tomography shows that the main reason for this difference is that dislocations lines are not planar in PoEM 11. Along a given dislocation line, one finds segments belonging to different planes. Some of these segments are even sessile and their origin will be discussed in the next section. Let us focus here on glissile segments. Most of them correspond to planes that are not significantly solicited from the macroscopic point of view. This means that many dislocation segments escape by cross slip from the hard slip planes where, under external loading, they are expected to glide into easy $\{110\}$ and (100) planes, probably under the influence of local stress heterogeneities. More than $60 \%$ of the dislocations indexed in PoEM 11 involve cross slip. This results in a three-dimensional dislocation microstructure, which is intrinsically less glissile and also, as shown below, enhances further dislocation interaction mechanisms.

\subsection{Sessile dislocation segment formation and sessile loop formation}

The pervasive occurrence of sessile loops of various sizes represents the other characteristics of our samples. The formation of the strings of loops described in Fig. 4 is well known. It has been observed in ceramics deformed at high temperature (e.g., Phillips et al., 1982a and b) and the formation mechanism has been discussed by Junqua \& Grilhé (1984) and Lagerlöf et al. (1989). It is related to the dipole interaction between non-screw segments. Dipoles first evolve into very long closed loops as those observed in Fig. 4. Indeed, Fig. 4b illustrates very well the mechanism proposed by Junqua \& Grilhé (1984) and Lagerlöf et al. (1989). By self-climb involving pipe diffusion, dipole fluctuations occur, which eventually leads by pinching to the formation of strings of loops. Further diffusion, in the bulk, leads to loop shrinking until they disappear. Collapse of loops has already been observed in olivine by Goetze \& Kohlstedt (1973), who measured the shrinkage kinetics.

However, complete annealing of loops by diffusion requires time (especially at low temperature) and many interactions occur and are indeed observed between those remaining loops and gliding dislocations. The occurrence of the many sessile dislocation segments observed along 

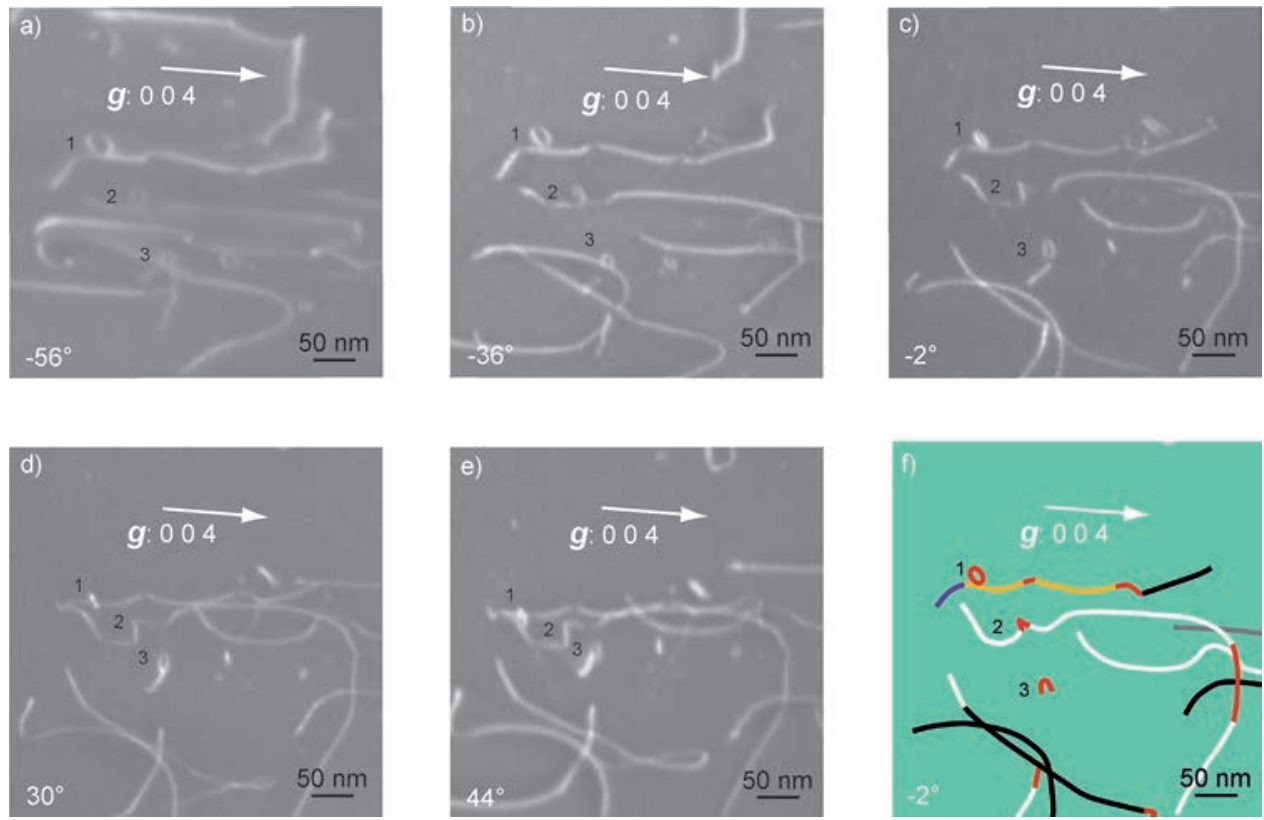

Fig. 7. Collinear interaction between a screw dislocation and a loop in PoEM 11. Micrographs obtained, with g: 004, where a family of three loops (labelled " 1 ", " 2 " and " 3 ") are in contrast (area extracted from Fig. 2a): projected angle of (a) $-56^{\circ}$; (b) $-36^{\circ}$; (c) $-2^{\circ}$; (d) $30^{\circ}$; and (e) $44^{\circ}$. The indexed micrograph (f) which corresponds to (c) (colour code of dislocation glide and climb planes is given in Table 2) shows that the red sessile segment, labelled " 2 ", comes from the collinear interaction of a screw dislocation and a sessile loop. (online version in colour)

the dislocation lines is interpreted as a result of these interactions involving collinear annihilations. This kind of interaction has been previously described by Mussi et al. (2015). The result is the so-called 'collinear interaction', involving annihilation, meaning the interaction of dislocations of opposite signs lying in different planes. An example of collinear interaction between a screw dislocation and a sessile loop is shown in Fig. 7. In this figure, which is extracted from the upper left corner of Fig. 2a, one can distinguish a family apparently composed of three sessile dislocation loops (labelled "1", "2" and "3") with diameters of around $30 \mathrm{~nm}$. Electron tomography enables us to see that dislocation loops " 1 " and " 3 " are indeed the loops that are not in contact with the long screw dislocation in the middle of the micrographs. On the other hand, dislocation loop " 2 " has interacted with the long screw dislocation. Indeed, when rotating the tilted series around the [001] direction (Fig. 7b-e), it is visible that the dislocation loop " 2 " is not a closed loop any more. Having interacted with the screw dislocation, it has produced helicoidally shaped sessile segment. This interaction mechanism has already been observed using TEM analysis (e.g., Fig. 5g in Mussi et al., 2015) and it has already been simulated by dislocation dynamics in zirconium (see Fig. 2 in Drouet et al., 2014). The interaction mechanism illustrated on Fig. $7 \mathrm{f}$ explains the occurrence of many sessile dislocation segments in the complex dislocations of Fig. 3 (in red and orange) and in Fig. 2. Indeed, collinear interactions with small and medium size dislocation loops (several $\mathrm{nm}$ to several tens of $\mathrm{nm}$ in diameter) can create sessile dislocation segments of different sizes.
The presence of sessile segments on a dislocation line impedes its motion. If the dislocation line has interacted with a very small loop, the sessile segment is small as well. It can be assimilated to a super jog and may be dragged under high stress. This sessile segment will act as a pinning which will leaves a string of small loops in its wake by dragging. This mechanism has been noted in Ti alloys (see Fig. 5b in Viswanathan et al., 2001) and is the origin of the microstructure shown in Fig. 6.

The occurrence of parallel sessile loops described in Fig. 5 can neither be explained by the break-up of dislocation dipoles by climb, nor by the debris dragging mechanism due to dislocation pinning. This mechanism cannot be explained up to now. Parallel sessile loops could be generated by a double cross-slip mechanism, but we found no intermediate configuration to support this assumption.

\section{Conclusion}

At $0.5 T_{\mathrm{m}}$, dislocation glide of [001] dislocations in $\{110\}$ and (100) represents the easiest deformation mechanism in olivine. Dislocation mobility is very anisotropic in those planes as shown in Fig. 1. Screw segments are straight indicating a high lattice friction. Hence the mobility of them is much lower than that of non-screw dislocations. In the absence of further interaction, the mobility of [001] screw dislocations in those planes represents the straincontrolling mechanism. Disorientating the sample from the orientation that activates the easier slip systems induces 
numerous cross-slip events which lead to complex, nonplanar, dislocation line geometries. This represents a first source of strain hardening. However, the non-screw dislocations may play a role as well. They can interact elastically leading to the formation of dipoles, which represent another strain hardening mechanism. Even at low temperature ( $c a .0 .5 T_{\mathrm{m}}$ ), local diffusion is sufficient to activate recovery mechanisms involving dipole breakdown into strings of loops, which eventually shrink and disappear (Fig. 4). This process is slow however and, before they disappear, these sessile loops represent numerous obstacles to dislocation glide. Interaction with the smallest loops leads to the formation of super-jogs, which impede dislocation glide (Fig. 6). Interaction with larger loops contributes further (i.e. besides cross-slip) to produce complex three-dimensional dislocation lines (red and orange parts on Fig. 3). The formation of these super-jogs can be described by the collinear annihilation mechanism (Madec et al., 2003; Mussi et al., 2015).

To conclude, electron tomography allows us to clarify the complex geometry of dislocations activity in olivine samples deformed at $0.5 T_{\mathrm{m}}$. The present study confirms the strong plastic anisotropy of olivine at low temperature and highlights the implication of the loading conditions (parameterized here by the sample orientation) on the dislocation activity. The elementary mechanisms at the origin of strain hardening as well as the counteracting recovery mechanism are described.

Acknowledgements: A Marie Curie fellowship awarded to S.D. (PoEM: Plasticity of Earth Mantle, FP7-PEOPLE20074-3-IRG, $\mathrm{N}^{\circ} 230748$-PoEM) supported the experimental work on which this study is grounded. The TEM national facility in Lille is supported by the CNRS (INSU) and the Conseil Régional du Nord Pas de Calais, France. This work was supported by funding from the European Research Council under the Seventh Framework Program (FP7), ERC grant $\mathrm{N}^{\circ}$ 290424-RheoMan to P.C.

\section{References}

Bulatov, V.V., Hsiung, L.L., Tang, M., Arsenlis, A., Bartelt, M.C., Cai, W., Florando, J.N., Hiratani, M., Rhee, M., Hommes, G., Pierce, T.G., Diaz de la Rubia, T. (2006): Dislocation multijunctions and strain hardening. Nature, 440, 1174-1178.

Demouchy, S., Mussi, A., Barou, F., Tommasi, A., Cordier, P. (2013a): Visco-plasticity of polycrystalline olivine at high pressure and $900^{\circ} \mathrm{C}$ : fresh outcomes from high resolution EBSD and electron tomography. AGU Abstracts [Fall Meeting, 2013], session T012, T43G-06.

Demouchy, S., Tommasi, A., Ballaran, T.B., Cordier, P. (2013b): Low strength of Earth's uppermost mantle inferred from tri-axial deformation experiments on dry olivine crystals. Phys. Earth Planet. Int., 220, 37-49.

Demouchy, S., Mussi, A., Barou, F., Tommasi, A., Cordier, P. (2014): Viscoplasticity of polycrystalline olivine experimentally deformed at high pressure and $900^{\circ} \mathrm{C}$. Tectonophysics, $\mathbf{6 2 3}$, 123-135.

Drouet, J., Dupuy, L., Onimus, F., Mompiou, F., Perusin, S., Ambard, A. (2014): Dislocation dynamics simulations of interactions between gliding dislocations and radiation induced prismatic loops in zirconium. J. Nucl. Mater., 449, 252-262.

Gaboriaud, R.J., Darot, M., Gueguen, Y., Woirgard, J. (1981): Dislocations in olivine indented at low-temperatures. Phys. Chem. Minerals, 7, 100-104.

Goetze, C. \& Kohlstedt, D.L. (1973): Laboratory study of dislocation climb and diffusion in olivine. J. Geophys. Res., 78, 5961-5971.

Hazen, R.M. (1976): Effects of temperature and pressure on the crystal structure of forsterite. Am. Mineral., 61, 1280-1293.

Herman, G.T., Lakshminarayanan, A.V., Naparstek, A. (1976): Convolution reconstruction techniques for divergent beams. Comput. Biol. Med., 6, 259-262.

Junqua, N. \& Grilhé, J. (1984): Apparitions d'instabilités sur des dipôles de dislocations coin. Acta Metall. Mater., 32, 2139-2147.

Lagerlöf, K.P.D., Mitchell, T.E., Heuer, A.H. (1989): Energetics of the break-up of dislocation dipoles into prismatic loops. Acta Metall. Mater., 37, 3315-3325.

Madec, R., Devincre, B., Kubin, L.P. (2002): From dislocation junctions to forest hardening. Phys. Rev. Lett., 89, 255508.

Madec, R., Devincre, B., Kubin, L., Hoc, T., Rodney, D. (2003): The role of collinear interaction in dislocation-induced hardening. Science, 301, 1879-1882.

Mei, S., Suzuki, A.M., Kohlstedt, D.L., Dixon, N.A., Durham, W.B. (2010): Experimental constraints on the strength of the lithospheric mantle. J. Geophys. Res., 115, B08204.

Messaoudi, C., Boudier, T., Sanchez Sorzano, C.O., Marco, S. (2007): TomoJ: tomography software for three-dimensional reconstruction in transmission electron microscopy. $B M C$ Bioinform., 8, 288.

Morniroli, J.P. \& Steeds, J.W. (1982): Microdiffraction as a tool for crystal-structure identification and determination. Ultramicroscopy, 45, 219-239.

Mussi, A., Cordier, P., Demouchy, S., Vanmansart, C. (2014): Characterization of the glide planes of the [001] screw dislocations in olivine using electron tomography. Phys. Chem. Minerals, 41, 537-545.

Mussi, A., Cordier, P., Demouchy, S. (2015): Characterization of dislocation interactions in olivine using electron tomography. Philos. Mag., 95, 335-345.

Paterson, M.S. (1970): A high pressure, high temperature apparatus for rock deformation. Int. J. Rock Mech. Min., 7, 512-517.

- (1990): Rock deformation experimentation. in "The BrittleDuctile transition in rocks: the Heard volume", A.G. Duba, W.B. Durham, J.W. Handin and H.F. Wang, eds. Geophysical Monograph Series. AGU, Washington, 187-194.

Penczek, P., Radermacher, M., Frank, J. (1992): Three-dimensional reconstruction of single particles embedded in ice. Ultramicroscopy, 40, 33-53.

Phakey, P., Dollinger, G., Christie, J. (1972): Transmission electron microscopy of experimentally deformed olivine crystals. in "Flow and fracture of rocks", H.C. Heard, I.Y. Borg, N.L. Carter and C.B. Raleigh, eds. Geophysical Monograph Series. AGU, Washington, 117-138.

Phillips, D.S., Mitchell, T.E., Heuer, A.H. (1982a): Climb dissociation of dislocations in sapphire $\left(\alpha-\mathrm{Al}_{2} \mathrm{O}_{3}\right)$ revisited: 
Crystallography of dislocation dipoles. Philos. Mag. A, 45, 371-385.

Phillips, D.S., Pletka, B.J., Heuer, A.H., Mitchell, T.E. (1982b): An improved model of break-up of dislocation dipoles into loops: Application to sapphire $\left(\alpha-\mathrm{Al}_{2} \mathrm{O}_{3}\right)$. Acta Metall. Mater., 30, 491-498.

Raleigh, C.B. (1968): Mechanisms of plastic deformation of olivine. J. Geophys. Res., 73, 5391-5406.

Raterron, P., Wu, Y., Weidner, D.J., Chen, J. (2004): Low-temperature olivine rheology at high pressure. Phys. Earth Planet. Int., 145, 149-159.

Raterron, P., Girard, J., Chen, J. (2012): Activities of olivine slip systems in the upper mantle. Phys. Earth Planet. Int., 200-201, 105-112.

Rebled, J.M., Yedra, L., Estrade, S., Portillo, J., Peiro, F. (2011): A new approach for 3D reconstruction from bright field TEM imaging: beam precession assisted electron tomography. Ultramicroscopy, 111, 1504-1511.

Vincent, R. \& Midgley, P.A. (1994): Double conical beam-rocking system for measurement of integrated electron diffraction intensities. Ultramicroscopy, 53, 271-282.

Viswanathan, G.B., Hayes, R.W., Mills, M.J. (2001): A study based on jogged-screw dislocations for high temperature creep in $\mathrm{Ti}$ alloys. Mater. Sci. Eng. A-Struct., 319-321, 706-710.

Zhong, S. \& Watts, A.B. (2013): Lithospheric deformation induced by loading of the Hawaiian Islands and its implications for mantle rheology. J. Geophys. Res., 118, 6025-6048.

Received 3 March 2015

Modified version received 24 June 2015

Accepted 17 July 2015 